\title{
Mitral valve replacement with aortic heterografts in humans
}

\author{
M. I. IONESCU, G. H. WOOLER, D. R. SM ITH, AN D \\ V. A. G R I M S H A W
}

From the Department of Thoracic Surgery, Leeds General Infirmary and Leeds University

\begin{abstract}
The complications associated with the implantation of prosthetic valves and the experimental attempts to graft the mitral valve are described. Because of the disadvantages connected with the use of artificial valves and as the experimental methods of grafting the mitral valve did not prove satisfactory for clinical use, the authors developed a technique for mitral valve replacement using heterologous aortic valves-reinforced by a semirigid Teflon ring-placed above the mitral annulus inside the atrial cavity. The technique of collecting, preparing, and inserting these grafts is described in detail. Using this method, seven patients with mitral incompetence or mitral disease were operated upon between February and April, 1967. One patient died five weeks after the operation from bacterial endocarditis in a period of severe hospital infection with staphylococcus. The other six patients had a very good clinical result immediately after surgery. At the present time they are symptom-free and have normal heart sounids. Clinical and experimental data: are discussed concerning the long-term fate of aortic heterografts in the mitral position.
\end{abstract}

Mitral valve replacement remains a surgical challenge. Clinical experience with prosthetic valves has shown a good percentage of satisfactory results, but at the same time the number of complications and accidents is high enough to state that there is no perfect artificial valve yet available. The variety of prosthetic valves in current use to-day lends support to this statement (Cartwright, Giacobine, Ratan, Ford, and Palich, 1963 ; Cartwright, Smeloff, Cayler, Fong, Huntley, Blake, and McFall, 1964 ; Cross and Jones, 1966 ; Gott, Daggett, Botham, Koepké, Zarnstorff, and Young, 1962 ; Kay, Zimmerman, and Suzuki, 1966; Magovern, Kent, and Cromie, 1963 ; Melrose, Bentall, McMillan, Flege, Alvarez Diaz, Nahas, Fautley, and Carson, 1964 ; Starr and Edwards, 1961).

There are many complications associated with the implantation of prosthetic valves.

1. Thrombosis on the prosthesis and embolism from either the valve cage, the ring, or the moving parts occurs in up to $42 \%$ of patients (Björk and Malers, 1964 ; Davila, Palmer, Sethi, de Laurentis, Enriquez, Rincon, and Lautsch, 1966 ; Garamella, Lynch, Schmidt, and Jensen, 1964 ; Groves, 1963 ; Herr, Starr, McCord, and Wood, 1965 ; Starr, 1964 ; Wooler, 1966). Emboli may occur early or late and the longer the follow-up period the greater is the incidence of embolism. The use of anti- coagulants, although reducing the incidence, does not completely prevent these complications.

2. Destruction of red cells is known to be produced by prosthetic valves (Brodeur, Sutherland, Koler, Kimsey, and Griswold, 1964) and in one reported instance the patient died from haemolysis (Reed and Dunn, 1964).

3. Mechanical failures of the prosthesis have been reported, such as dislodgement of the valve (Groves, 1963), change in shape and weight of the ball in the Starr-Edwards valve (Morse, 1965; Gerbode, 1965 ; Krosnick, 1965), the ball being extruded from the cage (Ablaza, Blanco, Maranhao, and Goldberg, 1965 ; Attar, Saunders, McLaughlin, Scherlis, and Cowley, 1966), and fracture of the silastic ball (Newman, Hoffman, and Gesink, 1967).

4. Regurgitation around the prosthesis and infection are common to all artificial valves.

5. Some patients develop a 'low cardiac output syndrome' after insertion of the Starr-Edwards prosthesis. The aetiology of this complication is not understood. Resection of papillary muscles to make room for the valve cage has been implicated as one cause for this syndrome (Dahlbäck and Schüller, 1963 ; Lillehei, Levy, and Bonnabeau, 1964). A small left ventricular cavity, as in mixed mitral lesions, filled with a large prosthesis producing trauma to the endocardium or interfering 
with the flow through the outflow tract may be another cause of altered cardiodynamics or postoperative arrhythmias. We believe that the papillary muscles and the ventricular wall can both interfere with the mechanism of the prosthesis.

6. Patients with good clinical results after a prosthetic replacement of the mitral valve may still have an impaired haemodynamic condition. Joyner (1966), using the ultrasound technique, and Judson, Ardaiz, Strach, and Jennings (1964), Morrow, Clark, Harrison, and Braunwald (1964), and Starr, Edwards, and Griswold (1962), performing complete haemodynamic studies in patients with a Starr mitral prosthesis, have shown that a diastolic gradient across the prosthesis is common and that the pulmonary artery pressure, normal at rest, rises during exercise. The cardiac output does not increase substantially after surgery and its increment with exercise is small.

The prosthetic valves, which in no way resemble normal leaflets in structure, perform a passive opening and closing function reasonably well. Inherent in their design, however, are features precluding an efficiency equal to that of normal leaflets.

To obviate the drawbacks of the prosthetic valves, homografts (Ross, 1962, 1963, 1964, 1967 ; Barratt-Boyes, 1964, 1965 ; Barratt-Boyes, Lowe, Cole, and Kelly, 1965) and heterografts (Binet, Duran, Carpentier, and Langlois, 1965 ; O'Brien, 1967 ; O'Brien and Clarebrough, 1966) have been used with success for replacement of the aortic valve.

Attempts to graft the mitral valve have proved more difficult. First, the mitral annulus of the patient with mitral incompetence is too large to admit a mitral graft from a normal human heart. Secondly, it is difficult to adjust the chordae to the correct length during operation, and even more difficult to judge their future required length when the left ventricle becomes smaller after corrective surgery. One of the authors (G. H.W.) has tried to use a mitral homograft for mitral replacement and found the diseased annulus too large to accommodate a human graft. On another two occasions he used mitral heterografts and, although the size was appropriate for the dilated annulus, it was impossible to adjust the length of the chordae correctly.

There are only two published reports regarding replacement of the mitral valve with grafts in humans. Murray, Roschlau, and Lougheed (1956) attempted to place an aortic valve segment in the left ventricle without success. Heimbecker, Baird, I_ajos, Varga, and Greenwood (1962) sutured an aortic homograft to the left ventricular side of the $\overrightarrow{\vec{s}}$ mitral annulus. The patient died one month later $\overline{0}$ from chest infection.

Although reports of mitral grafting in humans $\frac{\bar{\sigma}}{2}$ are few, there has been an impressive volume of $\mathbb{D}$ experimental work performed on animals. Berghuis, Rastelli, Van Vliet, Titus, Swan, and Ellis, (1964), Hubka, Šiška, Brozman, and Holec (1966),. Pappas, Titus, Berghuis, McKenzie, and Ellis $\overrightarrow{\vec{\omega}}$ (1966), Rastelli, Berghuis, and Swan (1965), and $\stackrel{\sigma}{\omega}$ Van Vliet, Titus, Berghuis, and Ellis (1965) used $\vec{x}$ mitral valve homotransplants in dogs with few encouraging results.

Lower and Shumway (1963) transplanted a homologous pulmonary valve in the mitralor annulus, and Lower, Stofer, and Shumway (1961)윽 replaced the mitral valve with an autologous pul-monary valve with better results.

A number of authors (Bigelow, Yao, Aldridge, Heimbecker, and Murray, 1964 ; Heimbecker et $\vec{\bullet}$ al., 1962 ; McKenzie, Pappas, Titus, and Ellis, 1966a ; Murray et al., 1956 ; Pappas et al., $1966 ;$ Willman, Zafiracopoulos, and Hanlon, 1961) transplanted a homologous aortic valve segment in the mitral area, suturing the base of the transplant to the mitral annulus and the tops of the $\frac{0}{\mathbb{D}}$ three commissures inside the left ventricle.

Mackenzie and others (McKenzie, Titus, Ellis, $\overrightarrow{\overrightarrow{0}}$ and Pappas, 1965; McKenzie et al., 1966a; McKenzie, Titus, Rastelli, Pappas, and Ellis, 1966b) used the same approach to replace the mitral valve. They reinforced the aortic valve homograft with Teflon and placed it down into the ventricle with the commissures sutured to the left $t^{x}$ ventricular myocardium. They came to the con-3.3. clusion that this 'technique is unsatisfactory for clinical use as all long-term survivors develop? mitral stenosis due to the contraction of the aortic cuff of the grafted valve. The cusps of grafted? valves remained pliable, mobile, and only slightly thickened up to twelve months after insertion'.

These reports make it clear that the two main techniques used have been mitral homotransplantations, with the difficulties of adjusting the $\mathrm{e}^{\omega}$ desired length of chordae, or the ventricular fixation of an aortic homograft, with the samec impediment of giving the correct tension to the commissures of the aortic cusps.

Because these methods did not prove satis- $\frac{0}{0}$ factory for clinical use we have developed since December 1966 an original technique for mitral valve grafting using heterologous aortic valvese placed above the mitral annulus inside the atriato cavity, the graft being reinforced by a Teflon ring. 
We present in this paper our clinical experience in seven patients operated upon using this method and our technique of preparation and insertion of an aortic graft in the mitral position.

\section{SURGICAL TECHNIQUE}

COLLECTION OF GRAFTS The aortic grafts are taken from pigs $1 \frac{1}{2}$ to 2 years old and weighing between 200 and $300 \mathrm{~kg}$. at the time of death. They are collected without sterile precautions immediately after slaughter of the animal, and dissection and trimming of the aortic valve is performed in the next few hours. As much connective tissue and myocardium is removed as possible. The aorta is cut about $2 \mathrm{~mm}$. above the commissures of the aortic valve and a rim of tissue, $2 \mathrm{~mm}$. wide, is left below the sinuses of Valsalva. The aortic cuff is cut in a fluted shape, shorter at the commissures and larger at the middle of the cusps.

At this stage the inside diameter of the valve is measured from both the ventricular and the aortic side and the result is recorded. The valve is then placed in cold saline and sent to the tissue bank. The processing technique used is that previously described by Barratt-Boyes (1965), i.e., sterilization with $\beta$-propiolactone, instant freezing at $-80^{\circ} \mathrm{C}$., and freezedrying.

PREPARATION OF GRAFT AND TEFLON RING AT TIME OF SURGERY Before operation the size of the aortic graft is selected in relation to the size of the heart and the type of mitral disease present. Grafts with an internal diameter of between 30 and $38 \mathrm{~mm}$. (as measured from the aortic side) are considered sufficient to adapt to any mitral annulus. The selected graft is reconstituted a few hours before operation in saline (containing 50 units $/ \mathrm{ml}$. heparin, 100 units $/ \mathrm{ml}$. penicillin, and $0.2 \mathrm{gr}$./1. streptomycin) at a temperature of $40^{\circ} \mathrm{C}$. The graft is then ready for attachment to a Teflon ring.

A selection of semi-rigid Tefion rings $(3 \mathrm{~mm}$. in thickness and 34 to $40 \mathrm{~mm}$. internal diameter) covered with Teflon cloth have been prepared and sterilized in advance. We have used two types of Teflon ring, both conical in shape, to accommodate well to the shape of the graft. One type, as shown in Fig. 1, covers only two-fifths of the aortic graft. At the time of surgery it is sutured to the graft by a continuous running suture at the inferior margin and by interrupted stitches at the superior margin. The second type of Teflon ring (which is now preferred) covers the graft completely by having a long sleeve (Fig. 2). This type of ring is sutured to the aortic graft by a single row of interrupted stitches at the superior margin. The coronary ostia of the graft are closed by interrupted stitches, whichever type of Teflon ring is used.

INSERTION OF GRAFT AND TEFLON RING Stitches are prepared for the fixation of the aortic graft and

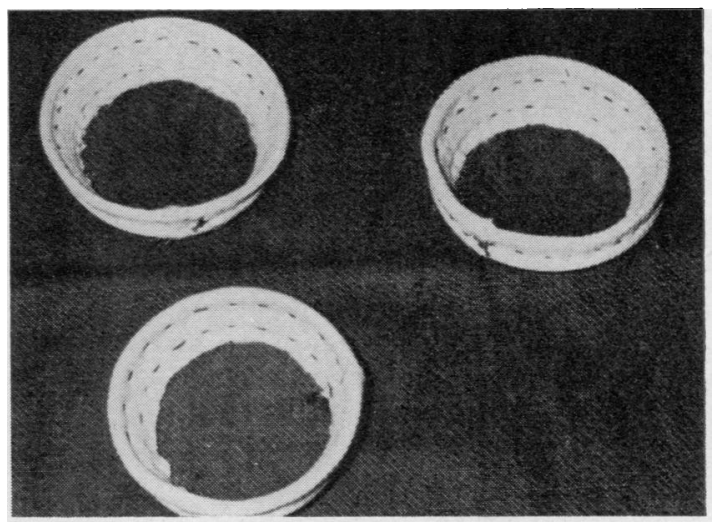

FIG. 1. Short ring. Plain semi-rigid Teflon ring covered with knitted Teflon cloth.

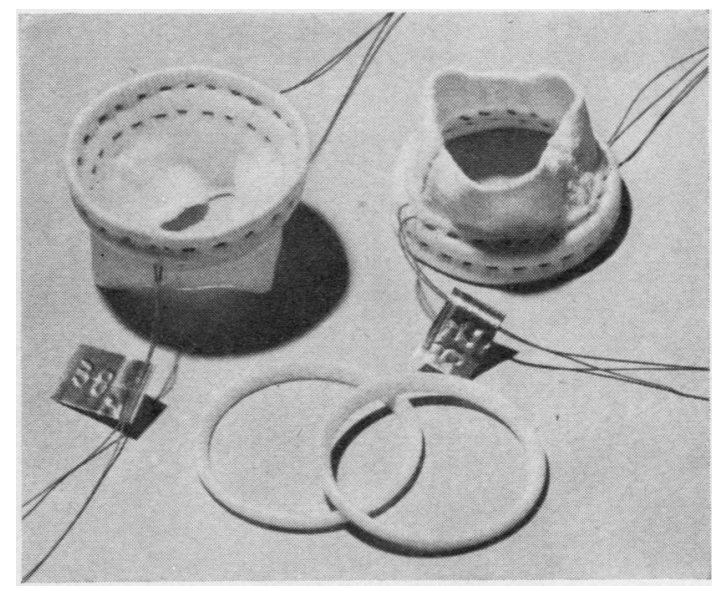

FIG. 2. Long sleeve ring. Plain semi-rigid Teflon ring covered with knitted Teflon cloth showing the two adjusting threads by which the shape of the ring can be altered.

Teflon ring to the mitral annulus. Between 14 and 16 no. 1 Mersilene double-needle sutures are inserted through the aortic wall of the graft from the inside. Care is taken to place three stitches across each commissure. All stitches are placed astride a no. 2 Mersilene loop, positioned inside the graft, to prevent tearing of the aortic wall. The free ends of this loop are brought out through the aortic wall with the aim of being tied when the final measurement is made inside the heart. By adjusting the tension of this loop, the diameter of the aortic cuff of the graft can be varied by a few millimetres to provide perfect adaptation to the size of the mitral annulus. All is now ready for the insertion of the graft. Needles are fixed apart on three small towels to facilitate manipulation and the valve is left in heparinized saline with antibiotics until the actual moment of insertion (Figs 3, 4 , and 5). 


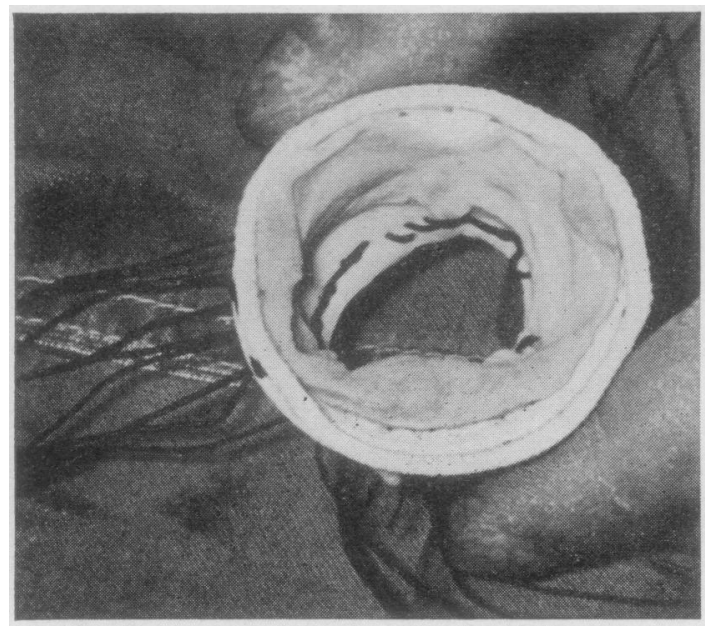

FIG. 3. Looking from above (the atrial aspect of the graft) to show the suturing stitches placed across the aortic wall and astride the Mersilene loop.

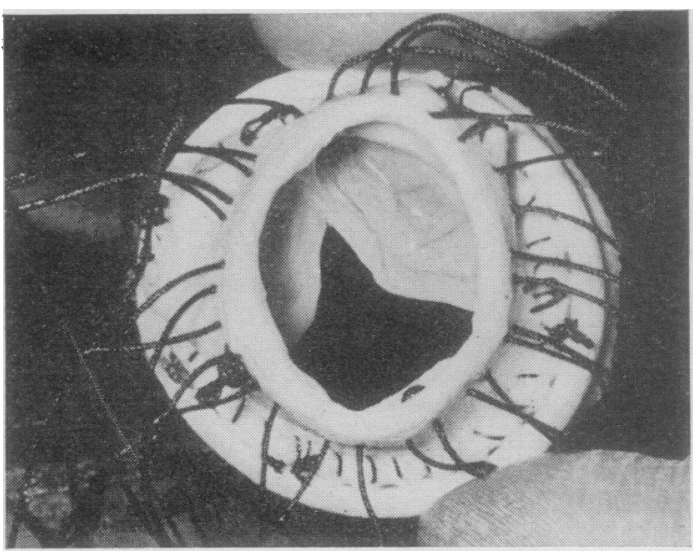

FIG. 4. Looking from below (the ventricular aspect of the graft) the continuous running suture joining together the Teflon ring and the graft is seen. The thick threads (no. 1 Mersilene) are passed through the aortic wall.

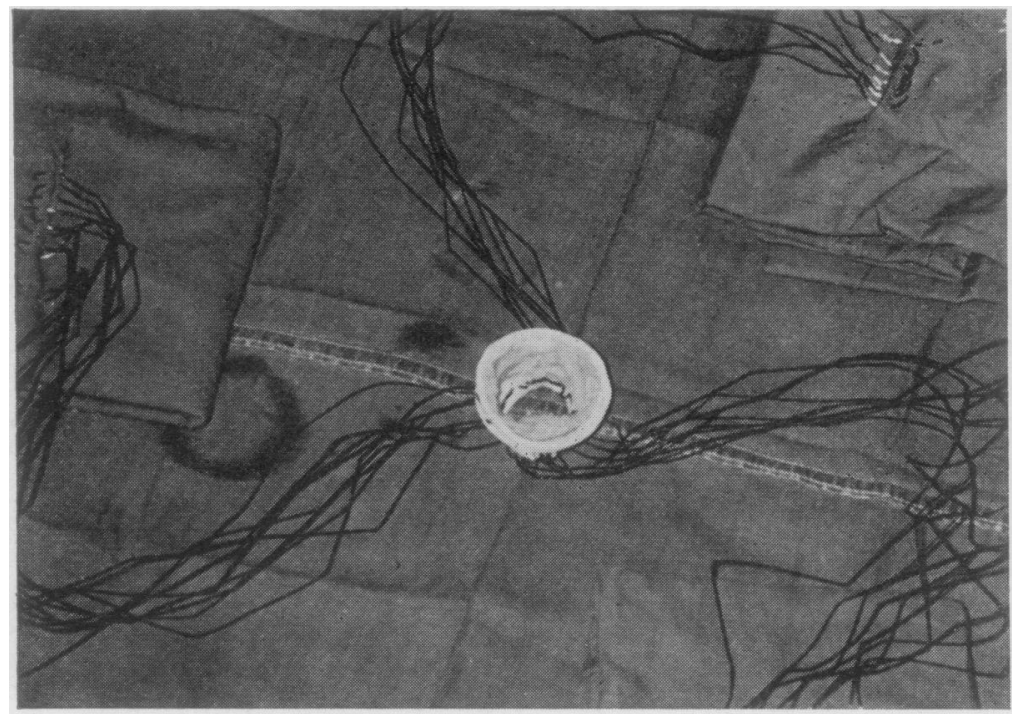

FIG. 5. Aortic heterograft reinforced with a Teflon ring and provided with stitches ready for insertion.

The diseased mitral valve is excised, leaving a ring of 2 to $3 \mathrm{~mm}$. of valve tissue behind. The aortic graft with its attached Teflon ring is orientated in such a way as to place the largest aortic cusp towards the aortic part of the mitral annulus.

The double needle sutures, which had previously been passed through the aortic wall of the graft and Teflon cloth in the long sleeve rings from the inside, are now taken one by one through the mitral annulus from below, starting from the anterior commissure. 


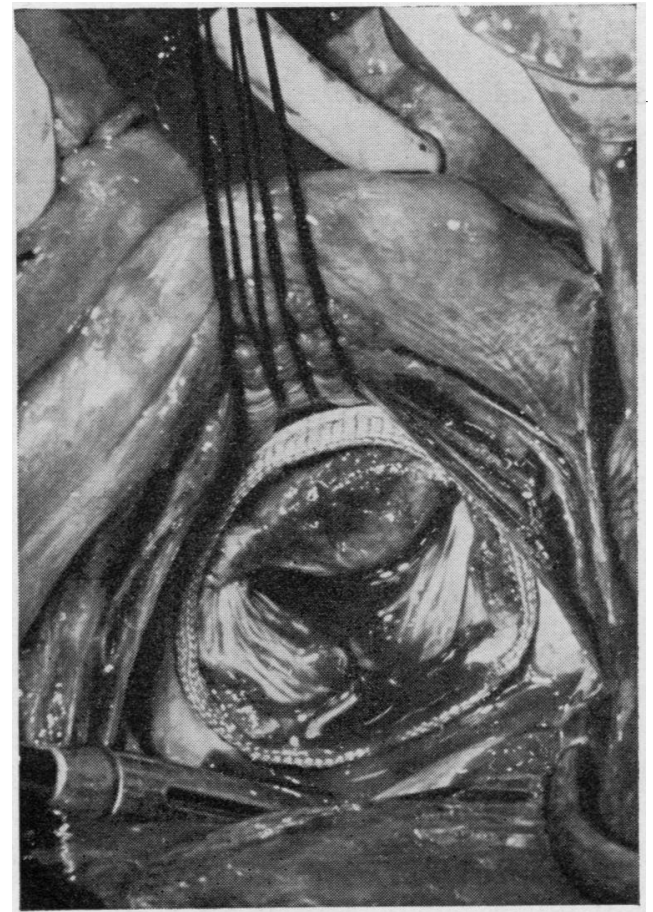

FIG. 6
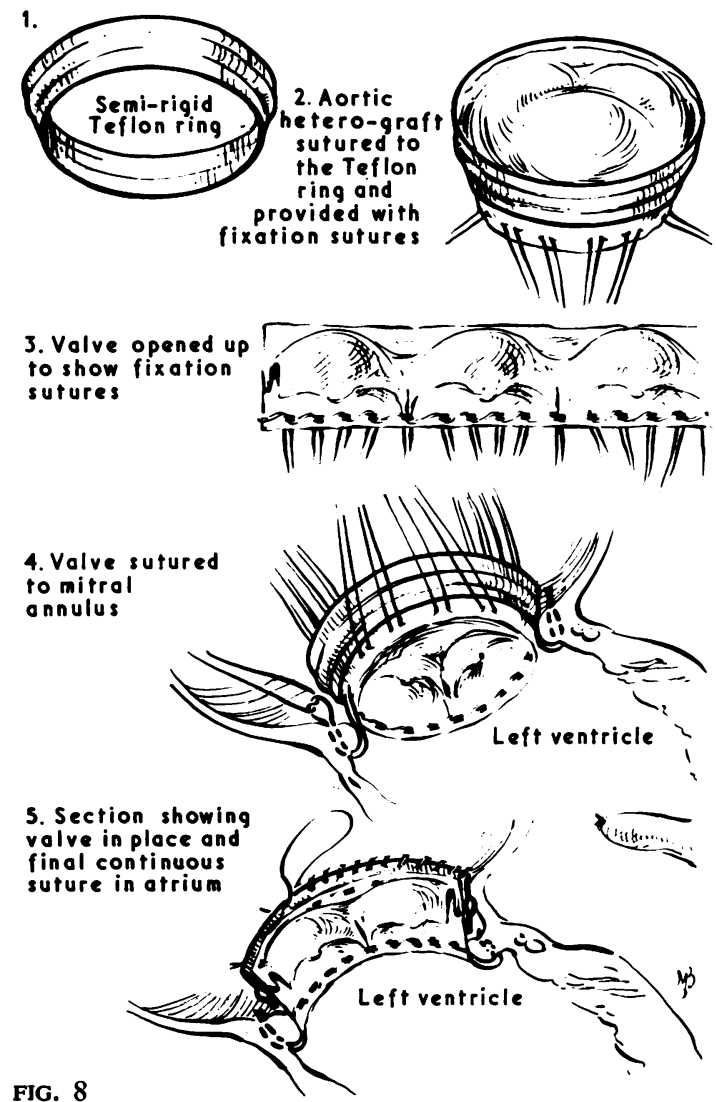

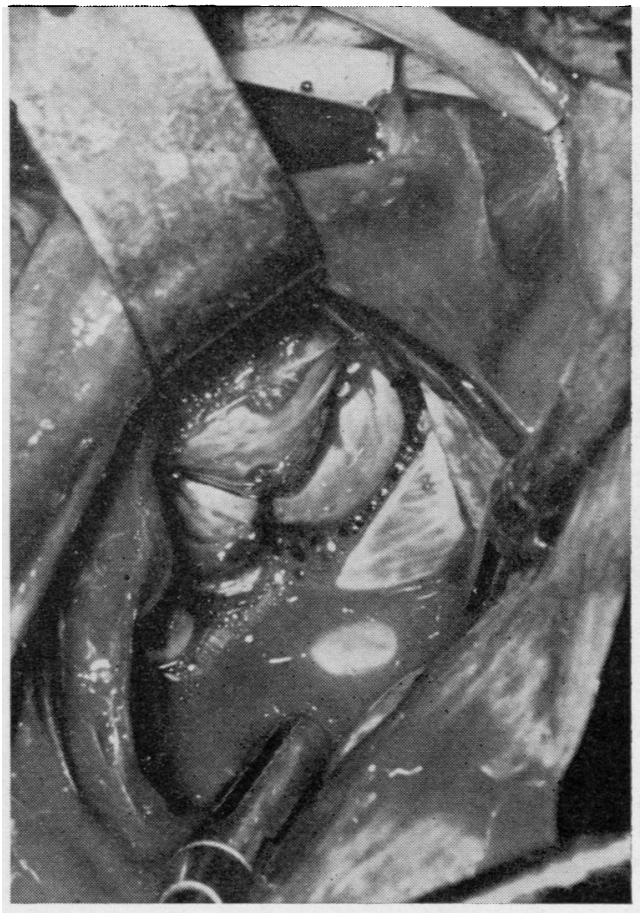

FIG. 7

FIG. 6. Aortic graft in position inside the atrium. The interrupted stitches were passed through the mitral annulus and tied. The largest aortic cusp was positioned towards the aortic part of the mitral annulus. Four pairs of threads were kept to expose the valve.

FIG. 7. Aortic graft in its final position above the mitral annulus. The upper part of the Teflon ring was secured to the atrial wall with a running suture. The valve was allowed to become competent for a short time.

FIG. 8. Schematic representation of preparation and insertion technique of an aortic heterograft in the mitral position. The short, semi-rigid Teflon ring (1) was attached to the graft (2). The sutures were placed through the aortic wall astride a strong Mersilene loop (3). Part of the interrupted stitches were passed through the mitral annulus and the graft was lowered into position (4). The insertion of the graft is completed by a continuous running suture securing the upper part of the Teflon ring to the wall of the left atrium (5). 
stitches from inside the atrium and the operation is concluded in the conventional manner (Fig. 8).

\section{CASE REPORTS}

We have inserted aortic heterografts in seven patients between February and April 1967. All the patients were operated upon using a Melrose heart-lung machine, high flow, haemodilution, and mild hypothermia. The perfusion time was between 60 and 90 minutes. During the whole open-heart procedure the heart was allowed to beat and a vent needle (Groves and Effler, 1964) was used in the ascending aorta.

CASE 1 C. J., a 37-year-old woman with mitral incompetence, has had for the past three years extreme exertional dyspnoea, orthopnoea, peripheral oedema, chronic bronchitis, and persistent tachycardia (sinus rhythm 110 to 120 ) in spite of digitalization. At operation a grossly incompetent mitral valve with ruptured chordae was removed and replaced with an aortic heterograft $(34 / 36 \mathrm{~mm}$. i.d.) reinforced with a short Teflon ring. She had a smooth post-operative course except for persistent tachycardia. She left the hospital improved and in a good clinical condition. Cardiac output measured on the second post-operative day was 3.51 . (4.5 1. during catheterization two years ago).

CASE 2 K. W., a 32-year-old man with mitral incompetence, has had for the past four years exertional dyspnoea, orthopnoea, palpitation, and peripheral oedema. He was treated with digoxin and anticoagulants for the past four years tor atrial fibrillation. At operation the typical sequelae of subacute bacterial endocarditis of the mitral valve and chordae were found. The mitral valve was replaced with an aortic heterograft $(32 / 36 \mathrm{~mm}$. i.d.) reinforced with a short Teflon ring. The patient made a very smooth recovery except for a small haemothorax. Three weeks after the operation he was in a good general condition but developed a temperature of $99^{\circ}$ to $100^{\circ} \mathrm{F}$., splenomegaly, and atypical mononuclear cells. This was thought to be a post-perfusion syndrome. All antibiotics were discontinued at that time because of allergic phenomena. One month after the operation he developed tachycardia and tachypnoea and the temperature rose to $100^{\circ}-103^{\circ} \mathrm{F}$. A blood culture at that time was negative. A week later he died. Another blood culture taken three days before death was found to be positive for Staphylococcus aureus. At that time we had a severe hospital infection with staphylococcus. Post-mortem examination revealed bacterial endocarditis on the grafted valve. The Teflon ring was completely covered by endothelium, and, although covered with vegetations, the cusps of the grafted valve remained competent. During the whole post-operative course this patient had normal heart sounds. The cardiac output measured at the end of the operation was 71 . and 24 hours later $4 \cdot 2$ litres.
CASE 3 M. F., a 46-year-old woman with mitral valve disease, gave a clinical history of rheumatic chorea $\stackrel{\oplus}{?}$ at the ages of 9,11 , and 14 years. For 10 years she had had chronic bronchitis, tor six years exertional 흠 dyspnoea, palpitations, and peripheral oedema, and $\frac{\bar{S}}{\bar{D}}$ for two years haemoptysis, orthopnoea, and tiredness. $\mathbb{D}$ Digoxin and anticoagulants had been started five $\frac{\Omega}{\Omega}$ years previously when she developed atrial fibrilla- $\infty$ tion, and she had been taking diuretics for four years $\overrightarrow{0}$ prior to her admission to hospital. The pulmonary function tests showed obstructive airway disease $\vec{\omega}$ (F.E.V. $53 \%$ ). At operation the mitral valve, cornpletely destroyed, stenotic, and incompetent, was $\overrightarrow{\vec{x}}$ removed and replaced with an aortic heterograft in (32/36 mm. i.d.) reinforced with a short Teflon ring. N Intermittent positive pressure respiration was maintained through a tracheostomy tube for 10 days. Of Immediately after the operation the patient developed a typical low output syndrome. (Cardiac output measured on the first post-operative day was $1.51 ., \overrightarrow{ }$ compared with $3 \cdot 2$ l. found in 1965.) She was treated for eight days with a continuous intravenous drip of isoprenaline to which she responded well and then $\vec{\bullet}$ the intusion was gradually discontinued. She improved dramatically and was discharged from hospital symptom-tree with normal heart sounds.

CASE 4 J. M., a 33-year-old woman with gross mitral incompetence and slight aortic incompetence, had rheumatic fever at the age of 12 and subacute $\frac{\circ}{D}$ bacterial endocarditis at the age of 20 years. She had had severe exertional dyspnoea for 12 years and $\overrightarrow{\overline{0}}$ peripheral oedema for the past seven years. Four and 3 a half years ago she developed atrial fibrillation with acute left heart tailure. Since then she had been taking digoxin, propranolol (Inderal, I.C.I. Ltd.), and diuretics with no improvement. At operation almost the entire aortic cusp of the mitral valve was found to be detached from the papillary muscles by ruptured chordae. The valve was replaced with an aortic heterograft $(34 / 36 \mathrm{~mm}$. i.d.) reinforced with a short Teflon ring. At the end of the procedure the heart went into sinus rhythm. The patient made an uneventful recovery. At the present time she has $ᄋ$ normal heart sounds and sinus rhythm and is symptom-tree.

CASE 5 R. J., a 35-year-old man with mixed mitral disease and slight aortic incompetence, had rheumatic fever at the age of 13 years. Ten years ago he started to have haemoptysis, chest pain, exertional dyspnoea, $\mathrm{N}$ and orthopnoea. For the past five years he had been $\sigma$ given digoxin and diuretics without obvious improvement. At operation a completely destroyed and heavily calcified mitral valve was removed and $\mathbb{E}$ replaced with an aortic heterograft $(34 / 36 \mathrm{~mm}$. i.d.) reintorced with a long sleeve Teflon ring. The cardiac $T$ output measured on the first post-operative day was 4.7 1. (a few weeks before the operation the cardiac $\cong$ output was 3.4 1.). The patient had a completely smooth post-operative course, and at the present time he has normal heart sounds and is symptom-free (Fig. 9). 


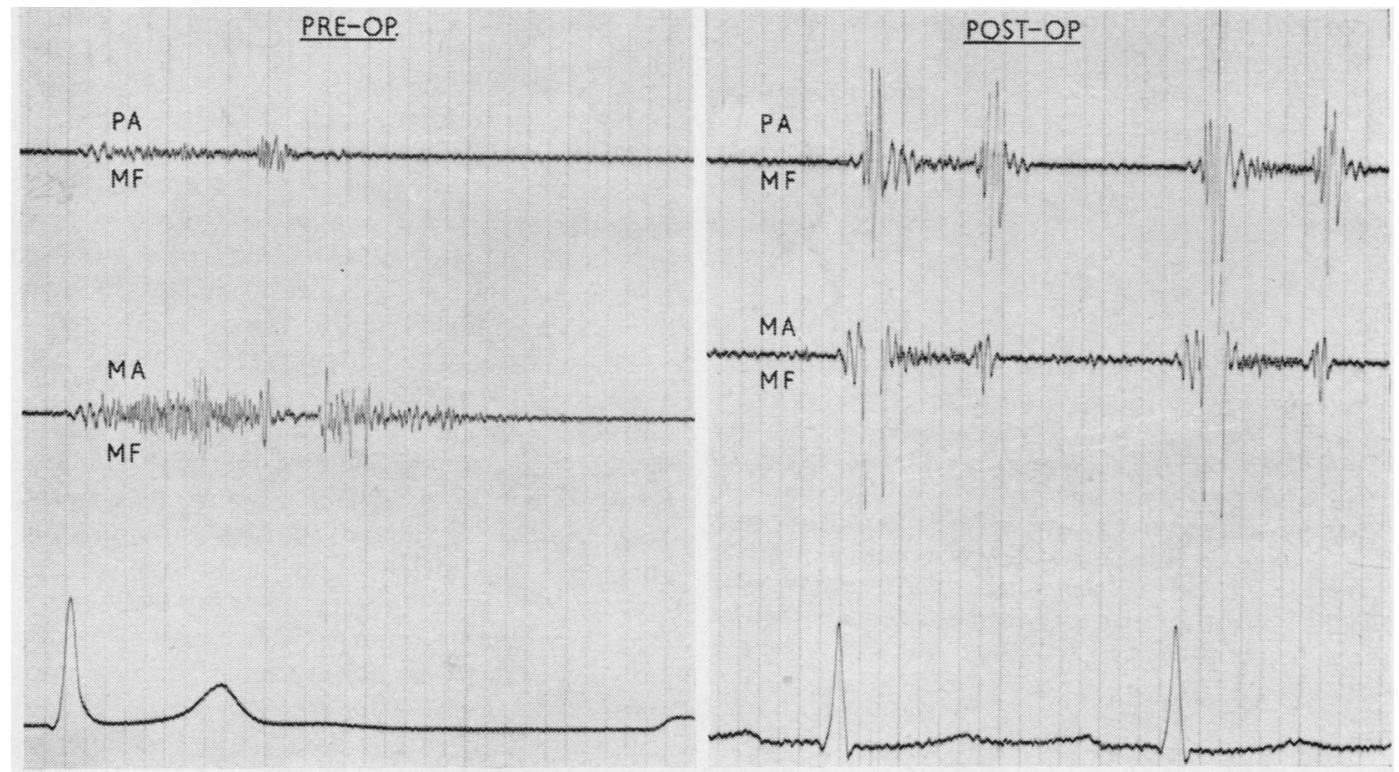

FIG. 9. Phonocardiogram of R. J. (case 5) (left) before and (right) after operation.

CASE 6 M. K., a 37-year-old man with mitral disease and moderate aortic incompetence, had rheumatic fever at the age of 12 years. A retinal artery embolism occurred when he was 24 years old. He had noted severe exertional dyspnoea for 14 years, chest pain, bronchitis, and frequent respiratory infections for the past five years. A closed mitral valvotomy was performed in 1959 without improvement. At his second operation in 1967 a large clot was removed from the left auricle and auricular appendage. A destroyed mitral valve, heavily calcified and mainly stenotic, was excised and replaced with an aortic heterograft $(34 / 36 \mathrm{~mm}$. i.d.), sutured previously to a long sleeve Teflon ring. The cardiac output measured immediately after the operation was 3.7 1. (during catheterization two weeks previously the cardiac output had been exactly the same). The post-operative course was uneventful. At the present time the patient has normal heart sounds and is free of symptoms.

CASE 7 J. C., a 38-year-old man with severe mitral incompetence, had rheumatic fever at the age of 10 years. Five years ago he became symptomatic (exertional dyspnoea and palpitation). He developed atrial fibrillation in 1963 and started to take digoxin. At operation the mitral valve showed severe regurgitation due to ruptured chordae. The appearances suggested that the lesion was a sequel of bacterial endocarditis. The diseased valve was completely excised and replaced with an aortic heterograft (36/40 mm. i.d.) sutured previously to a long sleeve Teflon ring. The cardiac output was 6.51 . on the first post-operative day. The post-operative course was uneventful. At the present time the patient has normal heart sounds and is asymptomatic.

\section{DISCUSSION}

We started work on mitral heterografts in an attempt to obviate the drawbacks and complications connected with the use of entirely artificial mechanisms. The reasons for using a semi-rigid Teflon ring in conjunction with the aortic graft may be summarized as follows:

1. It helps to position such a graft even in an enormously dilated atrium by bringing the atrial wall to the graft instead of allowing the graft to become distorted by the atrium.

2. It maintains the sinuses of Valsalva in an almost normal position. Suturing the graft (which is not a perfectly round structure) to a somewhat smaller Tefion ring puts the commissures under slight tension in the plane of the ring by increasing the radius on the side of the commissures, reducing at the same time the radius of the sinuses of Valsalva (Fig. 10A). Cutting the aortic cuff in a fluted shape (shorter on the commissure side and longer in the middle of the cusps) will produce the same effect, i.e., putting the commissures under slight tension, but in a vertical direction (Fig. 10B). These will prevent the valve from becoming incompetent.

3. The suture of the upper part of the valve to the atrial wall is greatly facilitated. 


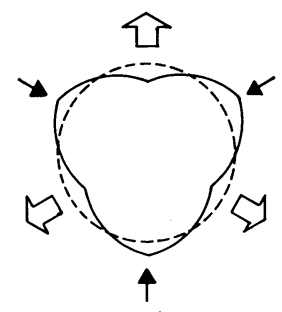

(A)

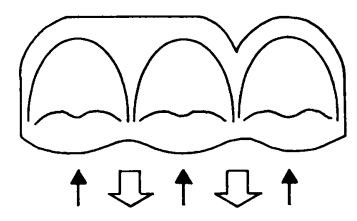

(B)
FIG. 10. Schematic representation of the mechanism by which the commissures of the aortic graft are put under tension. $(A)$ The dotted line represents the Teflon ring and the plain line the shape of the aortic valve at the level of Valsalva's sinuses. Suturing the valve to the ring will increase the radius on the side of the commissures and reduce it on the sinuses side. $(B)$ Cutting the aortic cuff in a fluted shape will put the commissures under tension in a vertical direction owing to the fact that after suturing the graft to the mitral annulus this fluted line will become a straight one.

4. The mechanical resistance of the aortic cuff is increased, although this part of the graft is reinforced by the atrial wall.

5. The manner of constructing these Teflon rings makes it possible to adjust their shape according to the graft anatomy (by tying one or other of the two threads placed in the ring it can be made more conical or more cylindrical).

The principal questions concerned with the use of aortic grafts in the surgical treatment of mitral valve disease relate to the long-term fate of the graft. In this regard the good clinical results obtained by Ross and Barratt-Boyes with aortic homografts in a sub-coronary position three to five years after the operation, substantiated by follow-up studies done one year after the operation (Davies, Lessof, Roberts, and Ross, 1965), are most encouraging. Pathological studies performed on aortic homografts by Hudson (1966) give evidence of good acceptance of the graft by the host tissues. Murray et al. (1956), Murray (1960), and Beall, Morris, Cooley, and De Bakey (1961) implanted aortic homografts in the descending aorta as a palliation for aortic incompetence with good results. Long-term follow-up studies (Kerwin, Lenkei, and Wilson, 1962) of patients operated on in 1956 by Murray showed no change in valve function. These patients are still alive more than 10 years after the operation.

There is good evidence of acceptance of heterograft valves by the host. Duran and Gunning (1965) proved, by implanting heterografts in the descending aorta of dogs, that the leaflets remain thin and pliable over a period of eight months. Binet et al. (1965) and Carpentier (1967) report ao good result with aortic heterografts after $17 \overline{\underline{ }}$ months of implantation; O'Brien (1967) and O'Brien and Clarebrough (1966) have goodळ results with aortic heterografts more than oneon year after operation. It appears from these studies? that there is no biological difference between $a \vec{\circ}$ homograft and a heterograft, their behaviour in $\overrightarrow{\vec{\omega}}$ humans being almost the same.

There are several advantages in using hetero $-\overrightarrow{\vec{x}}$ grafts, e.g., the available number of grafts is unlimited for all the required sizes; they are taken from young healthy animals and it is possible to have a large size aortic heterograft toc accommodate a dilated mitral annulus and ano enlarged left auricle. Our good clinical results immediately after surgery, together with the goode long-term results reported by others using homo $\frac{\odot}{<}$ and heterografts in the aortic orifice, are encour $-\vec{b}$ aging us to continue in this way.

Post-operative haemodynamic, phonocardio:graphic, and angiographic investigations are nowo being performed and the results will be reported soon.

The follow-up period of this group of seven⿳亠丷厂 patients is as yet too short to make any statemen concerning possible deleterious long-term effectso which may arise from using an aortic graft in the mitral position. We do not yet know whether the architecture of the aortic heterograft will change? in time, owing to the fact that a structure functionally adapted to the particular flow and? pressure pattern in the aortic orifice, has beenx put to work in a different haemodynamic environment.

We wish to thank Mr. F. Dexter for processing the grafts, Dr. M. El Gamal and Dr. R. Amarasingo ham, cardiologists attached to this department, Leslie? Catchpole, our senior pump technician, and the nursing staff and other technicians at the Infirmary who have helped us with this work.

\section{REFERENCES}

Ablaza, S. G. G., Blanco, G., Maranhao, V., and Goldberg, H. (1965) Fatal extrusion of the ball from a Starr-Edwards a ortic valvev prosthesis. Report of a case. J. thorac. cardiovasc. Surg., 50, 4010

Attar, S., Saunders, E., McLaughlin, J. S., Scherlis, L.. and Cowley, R. S. (1966). Prosthetic heart valve surgery: evaluation of earle and late complications. Ann. thorac. Surg., $2,52$.

Barratt-Boyes, B. G. (1964). Homograft aortic valve replacement ion aortic incompetence and stenosis. Thorax, 19, 131 .

(1965). A method for preparing and inserting a hom ograft aortico valve. Brit. J. Surg., 52, 847.

- Lowe, J. B., Cole, D. S., and Kelly, D. T. (1965). Homograf valve replacement for aortic valve disease. Thorax, $20,495$.

Beall, A. C., Jr., Morris, G. C., Jr., Cooley, D. A., and De Bakey M. E. (1961). Homotransplantation of the aortic valve. JQ thorac. cardiovasc. Surg., 42, 497.

Berghuis, J., Rastelli, G. C., Van Vliet. P. D., Titus, J. L., Swant H. J. C., and Ellis, F. H., Jr. (1964). Homotransplantation of then canine mitral valve. Circulation, 29, Suppl. 1, p.17. 
Bigelow, W. G., Yao, J. K., Aldridge, H. E., Heimbecker, R. O., and Murray, G. D. W. (1964). Clinical homograft valve transplantation. J. thorac. cardiovasc. Surg., 48, 333.

Binet, J. P., Duran, C. G., Carpentier, A., and Langlois, J. (1965). Heterologous aortic valve transplantation. Lancet, 2, 1275.

Björk, V. O., and Malers, E. (1964). Total mitral valve replacement: late result. J. thorac. cardiovasc. Surg., 48, 625.

Brodeur, M. T. H., Sutherland, D. W., Koler, R. D., Kimsey, J. A. and Griswold, H. E. (1964). Red cell survival in patients with aortic valvular disease and ball-valve prosthesis. Circulation, 30 , aor.

Carpentier, A. (1967). Personal communication.

Cartwright, R. S., Giacobine, J. W., Ratan, R. S., Ford, W. B. and Palich, W. E. (1963). Combined aortic and mitral valve replacement. J. thorac. cardiovasc. Surg., 45, 35.

-Smeloff, E. A., Cayler, G. G., Fong, W. Y., Huntley, A. C. Blake, J. R., and McFall, R. A. (1964). Total correction of Ebstein's anomaly by means of tricuspid replacement. Ibid., 47, 755.

Cross, F. S., and Jones, R. D. (1966). Laboratory and clinical experience with the caged lenticular valve. Dis. Chest, 50, 307.

Dahlbäck, O., and Schüller, H. (1963). Open correction of mitral insufficiency-a modification of the Starr-Edwards technique. Acta chir. scand., 126, 300 .

Davies, H., Lessof, M. H., Roberts, C. I., and Ross, D. N. (1965). Homograft replacement of the aortic valve. Follow-up studies in twelve patients. Lancet, 1, 926.

Davila, J. C., Palmer, T. E., Sethi, R. S., de Laurentis, D. A., Enriquez, F., Rincon, N., and Lautsch, E. V. (1966). The problem of thrombosis in artificial cardiac valves. In Heart Substitutes, ed. Brest, A. N., p. 25. Thomas, Springfield, Illinois.

Duran, C. G., and Gunning, A. J. (1965). Heterologous aortic valve transplantation in the dog. Lancet, $2,114$.

Garamella, J. J., Lynch, M. F., Schmidt, W. R., and Jensen, N. K. (1964). Fatal clotting of the Starr-Edwards mitral ball valve nineteen months postoperatively. J. thorac. cardiovasc. Surg., 47, 673.

Gerbode, F. (1965). In discussion of paper by Lillehei, C. W., Lillehei, R. C., Castaneda, A. R., and Ferlic, R. M. Aortic valve replacement utilizing the sutureless (Magovern) prosthesis. With particular reference to pathologic anatomy and choice of prosthesis. Ibid., 50, 499.

Gott, V. L., Daggett, R. L., Botham, R. J., Koepké, D. E., Zarnstorff, W. C., and Young, W.P. (1962). The development of a prosthetic heart valve utilizing a rigid housing and a flexible butterfly-wing leaflet. Trans. Amer. Soc. artif. intern. Organs, 8, 72.

Groves, L. K. (1963). In discussion of paper by Ellis, F. H., Jr., McGoon, D. C., Brandenburg, R. O., and Kirklin, J. W. Clinical experience with total mitral valve replacement with prosthetic valves. J. thorac. cardiovasc. Surg., 46, 493.

- - and Effler, D. B. (1964). A needle-vent safeguard against systemic air embolism in open-heart surgery. Ibid., 47, 349.

Heimbecker, R. O., Baird, R. J., Lajos, T. Z., Varga, A. T., and Greenwood, W. F. (1962). Homograft replacement of the human mitral valve. A preliminary report. Canad. med. Ass. J., 86, 805

Herr, R., Starr, A., McCord, C. W., and Wood, J. A. (1965). Special problems following valve replacement: embolus, leak, infection, red cell damage. Presented before the Society of Thoracic Surgeons, St. Louis.

Hubka, M., Siška, K., Brozman, M., and Holec, U. (1966). Replacement of mitral and tricuspid valves by mitral homograft. $J$. thorac. cardiovasc. Surg., 51, 195.

Hudson, R. E. B. (1966). Pathology of the human aortic valve homograft. Brit. Heart J., 28, 291.

Joyner, C. R., Jr. (1966). Hemodynamic performance of prosthetic heart valves. In Heart Substitutes, ed. Brest, A. N., p. 54. Thomas, Springfield, Illinois.

Judson, W. E., Ardaiz, J., Strach, T. B. J., and Jennings, R. S. (1964). Postoperative evaluation of prosthetic replacement of aortic and mitral valves. In American Heart Association Monograph No. 7, Cardiovascular Surgery, 1963. Circulation, 29, Supplement 1, p. 14

Kay, E. B., Zimmerman, H. A., and Suzuki, A. (1966). Prosthetic valves: long term results. In Heart Substitutes, ed. Brest, A. N., p. 72. Th ${ }^{2}$ mas, Springfield, Illinois.

Kerwin, A. J., Lenkei, S. C., and Wilson, D. R. (1962). Aortic valve homograft in the treatment of aortic insufficiency. New Engl. J. Med., 266, 852 .

Krosnick, A. (1965). Death due to migration of the ball from an aortic valve prosthesis. J. Amer. med. Ass., 191, 1083.

Lillehei, C. W., Levy, M. J., and Bonnabeau, R. C. (1964). Mitral valve replacement with preservation of papillary muscles and chordae tendineae. J. thorac. cardiovasc. Surg., 47, 533.

Lower, R. R., and Shumway, N. E. (1963). Replacement of the dog mitral valve with a homograft. Surg. Forum, 14, 247.
Stofer, R. C., and Shumway, N. E. (1961). Total excision of the mitral valve and replacement with the autologous pulmonic valve. J. thorac. cardiovasc. Surg., 42, 696.

Magovern, G. J., Kent, E. M., and Cromie, H. W. (1963). Sutureless prosthetic heart valves. Circulation, 27, 784

McKenzie, M. B., Pappas, G., Titus, J. L., and Ellis, F. H., Jr. (1966a). Replacement of canine mitral valve with preserved homologous aortic valves. J. thorac. cardiovasc. Surg., 52, 855.

- Titus, J. L., Ellis, F. H., Jr., and Pappas, G. (1965). Experimental semilunar valve homografts: morphologic features. Ibid., 50, 410. Rastelli, G. C., Pappas, G., and Ellis, F. H., Jr. (1966b). Replacement of the canine mitral valve with semilunar valves. Ibid., 51, 168.

Melrose, D. G., Bentall, H. H., McMillan, I. K. R., Flege, J. B. Alvarez Diaz, F. B., Nahas, R. A., Fautley, R., and Carson, J. (1964). The evolution of a mitral valve prosthesis. Lancet, 2, 623.

Morrow, A. G., Clark, W. D., Harrison, D. C., and Braunwald, E. (1964). Prosthetic replacement of the mitral valve, operative methods, and the results of preoperative and postoperative hemodynamic assessments. Circulation, 29, Suppl. 1, p. 2.

Morse, D. P. (1965). In discussion of paper by Lillehei, C. W., Lillehei, R. C., Castaneda, A. R., and Ferlic, R. M. Aortic valve replacement utilizing the sutureless (Magovern) prosthesis. With particular reference to pathologic anatomy and choice of prosthesis. J. thorac. cardiovasc. Surg., 50, 497.

Murray, G. (1960). Aortic valve transplants. Angiology, 11, 99.

- Roschlau, W., and Lougheed, W. (1956). Homologous aorticvalve-segment transplants as surgical treatment for aortic and mitral insufficiency. Ibid., 7, 466.

Newman, M. M. Hoffman, M. S., and Gesink, M. H. (1967) Mechanical failure of Starr-Edwards aortic prosthesis due to ball fracture. J. thorac. cardiovasc. Surg., 53, 398.

O'Brien, M. F. (1967). Heterograft aortic valves for human use. Valve bank techniques of measurement, and implantation. Ibid., 53, 392.

and Clarebrough, J. K. (1966). Heterograft aortic valve transplantation for human valve disease. Aust. med. J., $2,228$.

Pappas, G., Titus, J. L., Berghuis, J., McKenzie, M. B., and Ellis, F. H., Jr. (1966). Dog mitral valve homografts and heterografts. Surg. Forum, 17, 175.

Rastelli, G. C., Berghuis, J., and Swan, H. J. C. (1965). Evaluation of function of mitral valve after homotransplantation in the dog. J. thorac. cardiovasc. Surg., $49,459$.

Reed, W. A., and Dunn, M. (1964). Fatal hemolysis following ballvalve replacement of the aortic valve. Ibid., 48, 436 .

Ross, D. N. (1962). Homograft replacement of the aortic valve Lancet, 2, 487.

(1963). Surgical reconstruction of aortic valve. Ibid., 1, 571.

(1964). Homotransplantation of the aortic valve in the subcoronary position. J. thorac. cardiovasc. Surg., 47, 713.

(1967). Homograft replacement of the aortic valve-technique. Brit.J. Surg., 54, 165.

Starr, A. (1964). In discussion of paper by Magovern, G. J., Kent, E. M., Cromie, H. W., Cushing, W. B., and Scott, S. Sutureless aortic and mitral prosthetic valves. J. thorac. cardiovasc. Surg., 48, 360 .

- and Edwards, M. L. (1961). Mitral replacement. Clinical experience with a ball-valve prosthesis. Ann. Surg., 154, 726. - and Griswold, H. (1962). Mitral replacement: late results with a ball valve prosthesis. Progr. cardiovasc. Dis., 5, 298.

Van Vliet, P. D., Titus, J. L., Berghuis, J., and Ellis, F. H., Jr. (1965) Morphologic features of homotransplanted canine mitral valves. J. thorac. cardiovasc. Surg., 49, 504.

Willman, V. L., Zafiracopoulos, P., and Hanlon, C. R. (1961). Replacement of the mitral valve with homograft aortic valve. In Prosthetic Valves for Cardiac Surgery, ed. Merendino, K. A. p. 142, Thomas, Springfield, Illinois.

Wooler, G. H. (1963 and 1966). Unpublished data.

\section{ADDENDA}

By the time this article was completed Hubka, M., Šiška, K., and Holec, U., published (J. thorac. cardiovasc. Surg., 53, 260, 1967) an article describing 'replacement of the mitral valve with an aortic valve homograft implanted into the left atrium' in dogs.

Since this article was written another six patients have had this operation, bringing the total to thirteen. A second patient died due to a previous massive coronary embolus which was unsuspected before operation. The other 11 patients remain extremely well. 